\title{
EMPREGO FORMAL NA AGROPECUÁRIA DO ESTADO DE RONDÔNIA: UMA ANÁLISE DO COMPORTAMENTO DO MERCADO DE TRABALHO
}

\author{
Josineide Aquino da Silva Amaral ${ }^{1}$ \\ Luciana Virginia Mario Bernardo² \\ Jefferson Andronio Ramundo Staduto ${ }^{3}$
}

Resumo: O objetivo deste trabalho foi analisar o comportamento do emprego formal na agropecuária das microrregiões de Rondônia no período de 2011 a 2016. Os dados utilizados foram retirados do Cadastro Geral de Empregados e Desempregados - CAGED. Como resultado, a rotatividade no Estado de Rondônia é considerada alta para ambos os sexos. Os motivos para tal ocorrência podem estar ligados aos avanços tecnológicos e também a grande informalidade, que é característica deste setor. Outro fato identificado para estas microrregiões, é que o emprego reduziu nos anos de 2015 e 2016, desta forma, acredita-se que a crise econômica que afetou o país, pode ter influenciado o mercado de trabalho do Estado no setor da agropecuária.

Palavras-chave: Rotatividade. Crescimento do Emprego. Sexo. Agropecuária. Região Norte do Brasil.

\section{FORMAL EMPLOYMENT IN THE RONDÔNIA STATE AGRICULTURE: AN ANALYSIS OF BEHAVIOR OF THE LABOR MARKET}

Abstract: This work considered the formal behavior in the micro-regions of Rondônia in the period 2011 to 2016. The General Register of Employed and Unemployed CAGED. As a result, a turnover in the state of Rondônia is high for both sexes. The reasons for the complaint may be linked to technological advances and to the great informality, which is an element of the sector. Another fact identified for these microregions is the employment that reduced the years 2015 and 2016, in this way, the economic crisis that affects the country, can be influenced by the labor market of the State of agriculture and livestock.

Keywords: Rotativity. Employment Growth. Sex. Agriculture. Northern Brazil.

\section{EMPLEO FORMAL EN LA AGROPECUARIA DEL ESTADO DE RONDONIA: UN ANÁLISIS DEL COMPORTAMIENTO DEL MERCADO DE TRABAJO}

Resumen: El objetivo del este trabajo fue analizar el comportamiento del empleo formal en la agricultura de las microrregiones de Rondônia en el período de 2011 y 2016. Los datos utilizados fueron tomados del Catastro General de Empleados y Desempleados - CAGED. Como resultado, la rotación en el Estado de Rondônia se considera alta para ambos sexos. Los motivos para tal ocurrencia pueden estar vinculados a los avances tecnológicos y también a la gran informalidad, que es característica de este sector. Otro hecho identificado para estas microrregiones, es que el empleo disminuyó en los años 2015 y 2016, de esta forma, se cree que la

\footnotetext{
1 Unioeste, CCSA, Toledo, Brasil, jasaeconomia@hotmail.com, https://orcid.org/ 0000-0002-05872321

2 Unioeste, CCSA, Toledo, Brasil, lucianamario@yahoo.com.br, https://orcid.org/ 0000-0001-76150433

${ }_{3}^{3}$ Unioeste, CCSA, Toledo, Brasil, jstaduto@yahoo.com.br, https://orcid.org/ 0000-0003-1855-1292
} 
crisis económica que afectó al país, puede haber influenciado el mercado de trabajo del Estado en el sector de la agrocultura.

Palabras clave: Rotatividad. Crecimiento del empleo. Sexo. Agricultura. Norte de Brasil.

\section{Introdução}

O emprego formal está relacionado à maior segurança para o trabalhador em relação aos aspectos socioeconômicos. Para a De Almeida e Alves (2014) a formalização do trabalho contribui com o trabalhador e com a sociedade em que ele está inserido. Além dos benefícios individuais, como a seguridade social, a renda gerada, por exemplo, pode ampliar a comercialização de bens e serviços nos municípios em que são gerados estes empregos. Além disso, a formalidade possibilita o atendimento comercial das empresas governamentais. Proporcionando que esta comercialização, permita a circulação de recursos, que em outro cenário como o da informalidade, seria destinado a outras localidades.

A rotatividade é uma característica do setor agropecuário, o que pode estar relacionado as mudanças do mercado de trabalho rural, que tem sofrido alterações após a introdução de tecnologias nas propriedades rurais, nas diferentes culturas produtivas (STADUTO; SHIKIDA; BACHA, 2004). Em relação ao Norte do Brasil, região a qual está inserido o objeto desta pesquisa, Amaral e Silva (2015) consideram que existe uma alta taxa de rotatividade para os trabalhadores da agropecuária. Os homens possuem taxas de rotatividade maiores do que as mulheres e o nível de emprego no meio rural vem diminuindo, uma consequência das novas tecnologias implantadas ou da informalidade no campo.

A tendência é que este processo inovativo para a produção rural, seja cada vez mais intensificado, fazendo-se uso de ferramentais tecnológicos mais sofisticados, necessitando que a mão de obra se torne especializada. Desta forma, exigirá uma maior qualificação do trabalhador rural. Tendo em vista, o uso de práticas de geotecnologias e big data, por exemplo. Denominada como agricultura inteligente, o processo de gerenciamento da propriedade rural, poderá ser realizado remotamente, a partir dos dados gerados pelas novas tecnologias (WOLFERT et al., 2017; PIVOTO et al., 2016). A mesma, poderá influenciar o mercado de trabalho de forma a exigir outras habilidades dos produtores e trabalhadores rurais (GROGAN, 2012).

Dada as características do setor agropecuário, este trabalho analisou 0 emprego formal relacionado a este setor no Estado de Rondônia. Em 2010 o Estado 
tinha uma população rural de 417.853 habitantes, representando $26,77 \%$ da população total. Composto por 75.251 propriedades agrícolas, representando $18,22 \%$ dos estabelecimentos da região Norte (IBGE, 2006; IBGE, 2010). A Agropecuária teve uma participação de $11,9 \%$ no PIB do Estado em 2015. Se destaca na produção agropecuária bovinos, soja, leite e café. A carne bovina e a soja se sobressaem na exportação de Rondônia, em 2017 foram embarcadas 151,6 mil toneladas de carne e 878,1 mil toneladas de soja, gerando uma receita de 559,4 milhões de dólares e 332,8 milhões, respectivamente. O estado recebe grande parte da soja oriunda do Mato Grosso, onde é escoada pelo Rio Madeira (EMBRAPA, 2018).

O objetivo do trabalho foi analisar o comportamento do emprego formal na agropecuária no estado de Rondônia. O artigo está divido em 4 seções, sendo a primeira esta introdução, seguido pela segunda que fala sobre o mercado de trabalho, o terceiro seção fala sobre a metodologia e o último sobre a análise dos resultados e discussões e por último a conclusão.

\section{MERCADO DE TRABALHOAGRÍCOLA: UMA VISÃO GERAL}

Considera-se que a modernizaçãoagrícola não ocorre padronizada em todos as regiões brasileiras. A intensidade da modernização é diferente tanto nas regiões, quanto para as categorias de produtores. Além disso, no espaço agrícola do Brasil, tem ocorridos dois fenômenos não tradicionais e que influenciam a caracterização deste local. O primeiro é o desenvolvimento de atividades não agrícolas em áreas anteriormente destinadas a esta produção. O segundo é a formalização de espaços de lazer para aqueles que residem nas áreas urbanas (CARNEIRO, 1998). Mesmo com estas características peculiares, as atividades oriundas do espaço rural no país nos últimos anos, tem apresentado ganhos em relação a produtividade e tecnologia, fortalecendo os complexos agroindustriais do país, que ainda apresentam dependências no que refere-se a produção de matérias-primas (GASQUES et al., 2014; CASTRO et al., 2015).

Nos anos 90, a pobreza rural no Brasil foi constituída principalmente, pelas condições precárias a qual, as relações de trabalho estavam condicionadas. Faz parte deste contexto, diferentes características como a falta de cumprimento da legislação trabalhista, principalmente, para questões salariais, quanto nas questões estruturais oferecidas para os prestadores de serviço (KAGEYAMA, 1997). Porém, denota-se que ainda existem relações tumultuadas referentes ao mercado de 
trabalho rural, a jornada de trabalho, alimentação e transporte, para aqueles que não residem no espaço rural em que as atividades laborais são realizadas, são consideradas questões que podem exemplificar certame judicial. Ao qual, o trabalho escravo pode fazer parte do cenário rural, identificado a cada denúncia realizada (BUAINAIN et al., 2014).

A partir desta possibilidade de diversidade de características do rural brasiliero, denota-se que a poulação que vive em áreas rurais nas regiões Norte e Nordeste, podem sofrer com a pobreza quando seus domicílios são dotatos das características: (I) insuficiência de terra (área menor que um módulo fiscal); (II) domicílios com idosos sem aposentadoria ou pensão do Governo Federal; (III) trabalho informal; (IV) subocupação (jornada de trabalho inferior a 20 horas semanais); (V) domicílios sem beneficiários do Programa Bolsa Família. A maioria dos critérios apresentados estão relacionados ao trabalho rural (SOARES et al., 2016).

O interesse no mercado de trabalho não resulta apenas de envolvimento pessoal, mas também porque muitas questões de política social dizem respeito às experiências do mercado de trabalho, de grupos específicos de trabalhadores ou de vários aspectos da relação de emprego entre trabalhadores e empresas (BORJAS, 2005). No mercado de trabalho, a rotatividade pode ser considerada um problema para empresas e trabalhadores. Altos índices de rotatividade podem influenciar na baixa qualidade do emprego, pois a qualidade está relacionada a produtividade do trabalhador. Esta produtividade está vinculada a diferentes fatores, desde psicológicos a formação de capital humano. Neste caso, o capital humano é constituído pela formação escolar e pelos cursos e treinamentos oferecidos pelas empresas. Contudo, se a rotatividade é alta, os trabalhadores não terão tempo hábil para aquisição destes conhecimentos oferecidos pela organização (GONZAGA, 1998). No caso da região Norte, os resultados para a taxa de rotatividade média, entre os anos 2001 a 2010, para a agropecuária, correspondem para os homens em $198,02 \%$ em toda a região e $133,15 \%$ para as mulheres. Além disso, a rotatividade masculina cresceu $15,34 \%$ na década analisada e a feminina, 118,19\% (AMARAL; SILVA, 2015).

Em relação ao Brasil, sua história representa relações complexas para o mercado de trabalho, que ainda podem influenciar a inteiração entre patrões e colaboradores no decorrer das atividades laborais. O país foi o último a eliminar o trabalho escravo, ao qual, em grande parte, destinava-se as atividades rurais 
(DUARTE; MENDES, 2015). Assim, observa-se que "o trabalhador rural, que nos países que hoje são considerados desenvolvidos, foi valorizado justamente pela presença de opções, no Brasil, este trabalhador foi desvalorizado pela ausência de oportunidades" (BUAINAIN; DEDECCA, 2008, p. 52).

Além disso, as questões relacionadas aos direitos iguais entre homens e mulheres, também faz parte do espaço rural e de seu mercado de trabalho. Considerando os avanços na condição das mulheres na sociedade brasileira, 0 trabalho praticado e reconhecido no urbano e no rural é uma importante conquista. A mesma está relacionada a diferentes aspectos, como a escolarização e experiências femininas. Tendo em vista que a princípio, as mulheres eram condicionadas a atividades laborais com proximidade ou relação com seus afazeres domésticos, a diversificação destas atividades pode tornar mais acessível à permanência das mulheres no mercado de trabalho (BRUSCHINI; LOMBARDI, 2000).

Contudo, no espaço rural, a mulher ainda tem dificuldades para ter reconhecido seu trabalho, principalmente, quando este trabalho não está relacionado as atividades domésticas. Pois, cabe ao homem as atividades laborais vinculadas ao sistema produtivo da propriedade rural (HERRERA, 2012). Porém, observando o cotidiano das propriedades, pode-se perceber que as mulheres atuam em diferentes atividades tocantes aos tratos culturais da propriedade rural, mas isso não é reconhecido socialmente (NEVES; MEDEIROS, 2013). Assim, as divergências entre homens e mulheres no mercado de trabalho estão desde a diferença salarial paga a mesma função, até o reconhecimento das atividades laborais como trabalho profissional e não como uma "ajuda" aos familiares (BRUMER, 2000; SIMIÃO, 2002).

Para Staduto, Bacchi e Bacha (2004) não há cointegração dos salários dos trabalhadores permanentes entre as regiões do Brasil. No entanto, constata-se a existência de relação de equilíbrio entre os salários dos trabalhadores permanentes dentro de cada região. A possibilidade de existir algum grau de arbitragem em função do deslocamento dos trabalhadores das regiões menos desenvolvidas para as mais desenvolvidas em busca de maiores salários. A região Nordeste se destaca como a maior arbitradora dos salários dos trabalhadores temporários entre as regiões. Tal ocorrência é devido à grande mobilidade de mão de obra sazonal da região Nordeste com destinos as demais regiões. As diferenciações salariais entre as regiões são dispersas ao longo do tempo. A partir de 1990 essa dispersão e flutuações passam a diminuir sensivelmente. $O$ Nordeste possui a maior 
diferenciação salarial. A diferenciação salarial leva em consideração as características pessoais do trabalhador, como raça, sexo, escolaridade, experiência, as características do local de trabalho, como o tamanho do estabelecimento e o posto de trabalho ocupado pelo trabalhador (COELHO; CORSEUIL, 2002).

\section{METODOLOGIA}

Nesta seção apresenta-se a fonte de dados e a metodologia empregada no artigo. O modelo utilizado para mensurar os fluxos de trabalhadores na agropecuária e segue a metodologia Davis e Haltiwanger (1992). Além disso, foram organizados os resultados por sexo, para identificar possíveis diferenças entre homens e mulheres no mercado de trabalho rural de Rondônia.

Caracterização do local da pesquisa

No estado de Rondônia estimou-se que em 2010, haviam 1.562.409 pessoas, com densidade demográfica de 6,58 habitantes por quilômetro quadrado. Acreditase que tenha havido um aumento de $15 \%$ desta população, em 2017. Também foi identificado que a população urbana é maior que a população rural, porém $26,5 \%$ da população identificada em 2010 reside no espaço rural. Além disso, o rendimento médio aproximado do trabalho das pessoas de 16 anos ou mais, ocupado na semana de referência em trabalhos formais é de $\mathrm{R} \$ 1.952,00$ e com este mesmo perfil identificou-se que $55,3 \%$ das pessoas foram consideradas ocupadas em 2017 (IBGE, 2017a). O Estado localiza-se na região Norte do país (Figura 1).

$\mathrm{O}$ estado Rondônia é dividido em duas mesorregiões. A mesorregião Leste Rondoniense é formada por 42 municípios e a mesorregião Madeira-Guaporé, 10 municípios. Estes municípios estão organizados em 8 microrregiões, identificadas na Figura 1. 
Figura 1 - Localização de Rondônia, na região Norte do Brasil e suas Microrregiões

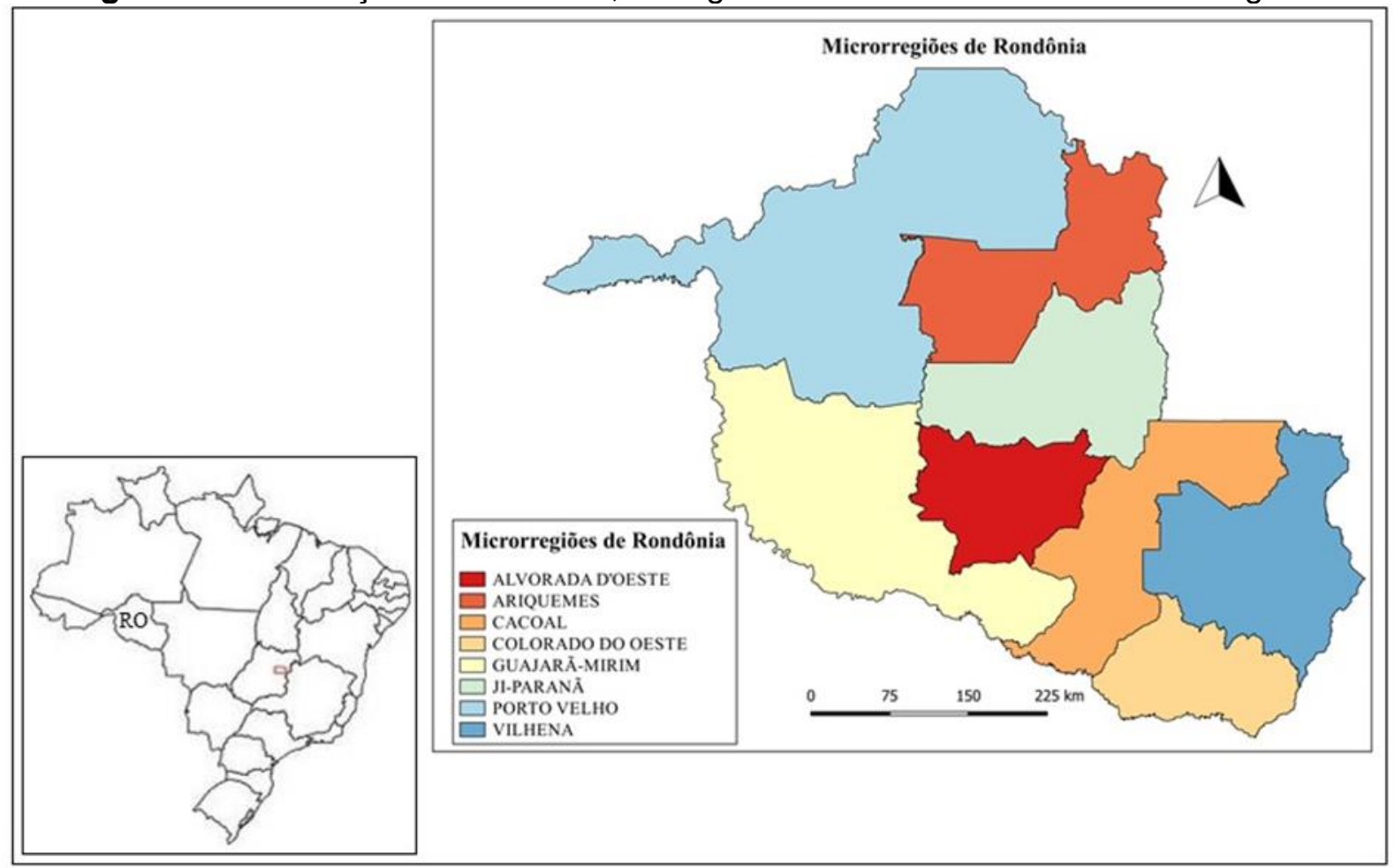

Fonte: elaborado a partir de IBGE (2015).

A Tabela 1 mostra o número de empregos formais no Estado de Rondônia nos anos de 2015 e 2016. A agropecuária em 2015 empregava 13.323 trabalhadores diretos e em 2016 caiu para 13.250, uma redução de 0,55\%. A agropecuária tem crescido no Estado nos últimos anos, principalmente na agricultura, com a entrada da soja no cenário rondoniense desde 1984, onde começou com uma área pequena de 400 hectare (ha). No início da década de 2000 a área para produção do grão já era de 90,4 mil ha e chegou na safra de 2016/2017 com 296 mil ha de área plantada (EMBRAPA, 2018, p. 11). O setor da administração pública possui o maior número de empregos para os dois anos, no entanto, houve uma queda de 2,85\% no emprego formal do setor. A construção civil teve a maior queda em termos percentuais, -37,75\% de 2015 para 2016. O Estado desde 2003 vinha tendo saldo positivo no estoque de trabalhadores, mas a partir de 2015 o cenário passa a ser desfavorável tanto para os trabalhadores rurais quanto para os urbanos. O que pode ser explicado pela crise econômica e política que o Brasil enfrenta desde 2015. 
Tabela 1 - Número de empregos formais segundo a atividade econômica - Rondônia 2015/2016

\begin{tabular}{l|r|r|r|r}
\hline \multirow{2}{*}{ Setores de Atividades Econômicas } & \multirow{2}{*}{2015} & \multirow{2}{*}{2016} & \multicolumn{2}{|c}{ Variação } \\
\cline { 4 - 5 } & & & Absoluta & Relativa (\%) \\
\hline Extrativo mineral & 1.302 & 1.277 & -25 & $-1,92$ \\
Indústria de transformação & 37.160 & 34.219 & -2.941 & $-7,91$ \\
Serviços industriais de utilidade pública & 3.385 & 3.875 & 490 & 14,48 \\
Construção civil & 20.393 & 12.694 & -7.699 & $-37,75$ \\
Comércio & 85.462 & 82.227 & -3.235 & $-3,79$ \\
Serviços & 77.435 & 76.882 & -553 & $-0,71$ \\
Administração pública & 120.201 & 116.773 & -3.428 & $-2,85$ \\
Agropecuária, extr. vegetal, caça e pesca & 13.323 & 13.250 & -73 & $-0,55$ \\
\hline TOTAL & 358.661 & 341.197 & -17.464 & $-4,87$ \\
\hline
\end{tabular}

Fonte: RAIS (2018).

O Estado de Rondônia aparece no cenário regional como o maior produtor de leite com 2,2 milhões de litros/dia, sendo que o município de Nova Mamoré é o líder em produção dentro do Estado (EMATER, 2018). A produtividade do café aumentou $235 \%$ nos últimos 17 anos apesar da área planta ter diminuído em quase $70 \%$. A produtividade se deve as novas variedades clonais e usos de tecnologias como poda e irrigação (EMBRAPA, 2018, p. 16). Rondônia é o quinto maior produtor de café do Brasil.

A produção bovina figura como uma das principais atividades econômicas de Rondônia, em 2017 o estado possuía 10,34 milhões de cabeças. O estado possui 17 frigoríficos com selo de inspeção federal (SIF) e cinco com selo estadual (SIE), além de alguns com inspeção municipal. Os municípios com maior número de rebanho de bovinos de corte são: Porto Velho (808.343), Nova Mamoré (427.906), Ariquemes (421.530), Cacoal (386.434) e Alta Floresta do Oeste (378.355). Em 2017, foram abatidos 2,634 milhões de animais no estado, considerando apenas os estabelecimentos sob inspeção federal (SIF) (EMBRAPA, 2018).

Fonte de dados

A base de dados utilizada é o Cadastro Geral de Empregados e Desempregados (CAGED) do Ministério do Trabalho e Emprego (MTE). Esta base de dados é alimentada com os dados fornecidos pelas empresas que fazem parte, neste caso, do setor agropecuário. Observa-se que caso não sejam disponibilizadas as informações, tanto a empresa, quanto o contador responsável pela declaração das informações, poderão ser punidos pela omissão, com multas e penalidades (FRANCO; CARDOSO, 2009). No CAGED, estas organizações declaram o número de pessoas que são admitidas e demitidas, no decorrer do ano. 
Neste trabalho foram utilizados os dados dos admitidos e demitidos na agropecuária das microrregiões de Rondônia, no período de 2011 a 2016. A análise foi feita por microrregião porque alguns municípios do estado não tinham dados registrados na base do CAGED.

\section{Medidas de avaliação}

Para avaliar a rotatividade do mercado de trabalho agropecuário foram utilizados os indicadores: taxa admissão, taxa de demissão e taxa de rotatividade, todos os indicadores têm com referência 0 estoque dos trabalhadores, $X_{t}$. Admissões (ADM) - total de pessoas assalariadas, com ou sem vínculo, admitidas pela empresa na unidade local durante 0 ano de referência da pesquisa. Desligamentos (DES) - total de pessoas assalariadas da unidade local que foram desligadas da empresa durante 0 ano de referência da pesquisa (demissão por decisão do empregador, por justa causa, por solicitação do empregado ou por acordo, aposentadoria, morte, etc) (IBGE, 2004).

$$
X_{t}=\frac{\left(\text { Empregados no ano } t+\text { Empregados no ano }_{t-1}\right)}{2}
$$

Em que o número de empregados no ano t é igual ao somatório de todos os vínculos empregatícios da agropecuária naquele ano.

As taxas de admissão TxAdm $t$ e de demissão TxDmt são dadas por:

$$
\operatorname{TxAdm}_{t}=\sum_{t=1}^{n}\left(\frac{\text { Nủmeros de Admissões }}{X_{t}}\right)
$$

Onde $\boldsymbol{T x}_{\boldsymbol{A}} \boldsymbol{A d \boldsymbol { m } _ { \boldsymbol { t } }}$ é a taxa de admitidos no ano, e é dada pelo número de admitidos dividido pelo estoque de trabalhadores $\left(\boldsymbol{X}_{\boldsymbol{t}}\right)$.

$$
\operatorname{TxDem}_{t}=\sum_{i=1}^{n}\left(\frac{\text { Nủmeros de dmissões }}{x_{t}}\right)
$$

Em que $\boldsymbol{T x D e m}_{t}$ é a taxa de demitidos no ano analisado, e é dada pelo número de demitidos no ano dividido pelo estoque de trabalhadores $\left(\boldsymbol{X}_{\boldsymbol{t}}\right)$.

A rotatividade dos trabalhadores na agropecuária (RTrab) é a soma da taxa de admissão e demissão, dada pela equação: 


$$
\operatorname{RTrab}_{t}=\operatorname{TxAdm}_{t}+\mathrm{TxDm} \mathrm{m}_{t}
$$

E representa o percentual de trabalhadores que mudaram de emprego ou se tornaram desempregados. A taxa de rotatividade quantifica todo o ajustamento no ano $t$ e constitui o percentual de trabalhadores que mudaram de emprego ou passaram da condição de empregados para desempregados. A taxa de rotatividade quantifica todo ajustamento dentro do setor agropecuário.

A taxa de crescimento líquido do emprego na agropecuária $\left(C L E A_{t}\right)$ é a diferença entre as taxas de admissão e demissão de trabalhadores no ano $t$.

$$
C L E A_{t}=\operatorname{TxAdm}_{t}-\operatorname{TxAdm}_{t}
$$

Os indicadores são analisados de forma agregada para o Estado de Rondônia e para o setor da agropecuária. Sendo que os dados foram analisados por sexo. As variáveis utilizadas são o vínculo empregatício, microrregião por unidade da federação, setor agropecuário, e as informações de admitidos e demitidos dentro do setor.

\section{RESULTADOS E DISCUSSÃo}

Nesta seção será feita uma análise do mercado de trabalho na agropecuária rondoniense. Primeiramente, foi analisada as taxas de emprego e desemprego, posteriormente, foi analisada a rotatividade do trabalho na agropecuária e por último, analisou-se a taxa de crescimento líquido no emprego agropecuário.

Análise das taxas de emprego e desemprego na agropecuária rondoniense.

As taxas de admissão e demissão são fundamentais para a composição da rotatividade. Altas taxas de admissão e demissão gera alta rotatividade. $O$ comportamento do mercado de trabalho na agropecuária nas microrregiões do estado no período de 2011 a 2016, indicam que o setor possui altas taxas de admissão e demissão, ficando evidente que os trabalhadores estão sujeitos instabilidade do emprego nesse setor. A maior taxa média de admissão para o sexo masculino foi no ano de 2011 com 107,30\%. Já a média para a taxa de demissão foi maior no ano de 2013 com 108,95\%. Para o sexo feminino a maior taxa de admissão ocorreu no ano de ano de 2011 com 109,59\% e a maior taxa de demissão no ano de 2016 com 139,45\%. Taxa de demissão maior que taxa de admissão 
significa que houve desemprego, ou seja, ocorreram mais demissões que contratações (Figura 2).

As altas taxas de admissão e demissão no setor agropecuário podem ser explicadas pela característica das atividades do setor. É importante lembrar que Rondônia possui mais 75 mil estabelecimentos agropecuários de agricultura familiar, o que representa quase $19 \%$ dos estabelecimentos da região Norte (IBGE, 2006). A agricultura está baseada no cultivo do feijão, arroz, milho, mandioca, soja e trigo. Sendo que a soja é o segundo produto mais exportado pelo estado. A produção da soja resultou em 765 mil toneladas na safra 2015/2016. Destaca-se os municípios Vilhena e Chupinguaia da microrregião de Vilhena e Corumbiara, Pimenteiras do Oeste, Cerejeiras e Cabixi da microrregião de Colorado do Oeste, como maiores produtores da cultura (IDARON, 2016).

Figura 2 - Taxa de admissão e demissão dos trabalhadores da agropecuária rondoniense de 2011 a 2016

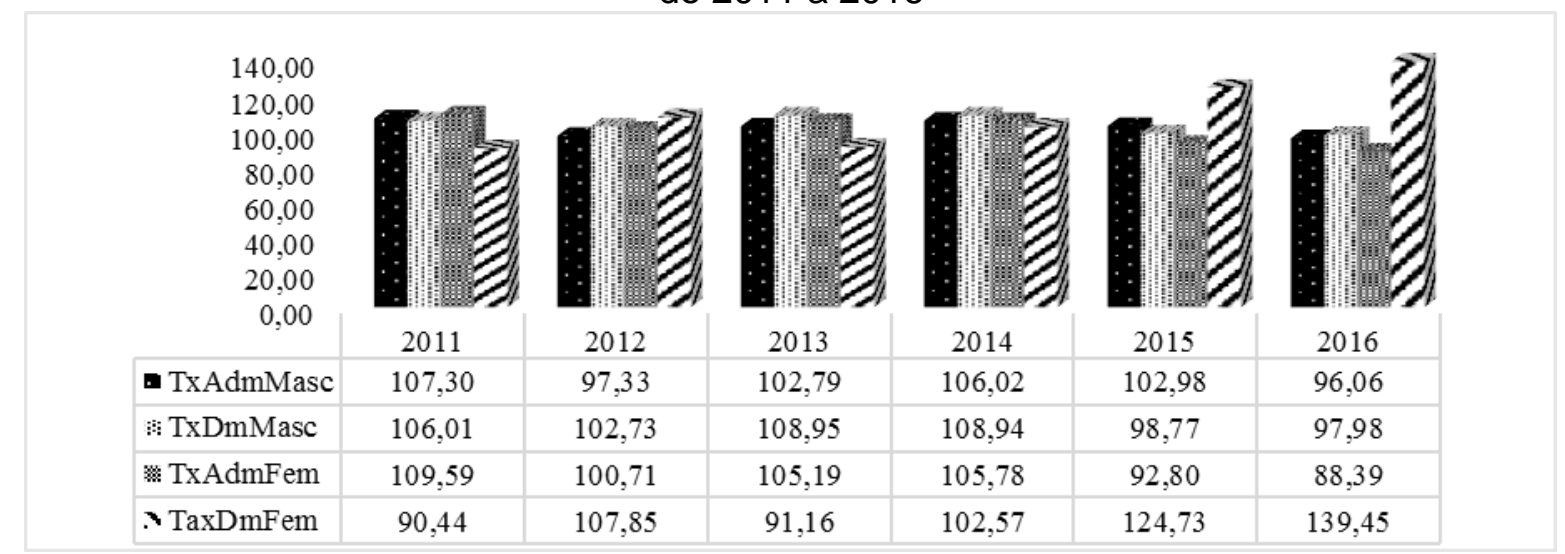

Fonte: Elaborado pelo autor, a partir de CAGED (2018).

As altas taxas de admissão e demissão prejudicam os trabalhadores e os empregadores. Quando um trabalhador é contratado ele gera um custo para o empregador, com o recrutamento, treinamento e leva tempo para se adaptar ao ambiente de trabalho. A demissão também incorre em custos. Os trabalhadores são prejudicados pois ficam desempregados e muitas vezes demoram para entrar em um novo emprego. É necessária a valorização do trabalhador rural para que este permaneça no espaço rural, por opção, como ocorre em países desenvolvidos (BUAINAIN; DEDECCA, 2008), considerando a importância da produção brasileira do agronegócio para alimentar parte do mundo.

Além disso, nos anos 90 a pobreza rural identificada no Brasil, estava atrelada a precariedade das relações de trabalho, para Kageyama (1997), as questões salariais, por exemplo, divergiam da legislação. Contudo, estas relações ainda são tumultuadas na atualidade, para os aspectos de jornada de trabalho, alimentação e 
transporte de trabalhadores. Faltam discussões, aprimoramentos legais e fiscalização, para que nas diferentes regiões brasileiras, seja extinto o trabalho escravo rural, que é identificado a partir de denúncias (BUAINAIN et al., 2014).

Análise da taxa de rotatividade

A rotatividade masculina na agropecuária das microrregiões rondoniense possui taxas elevadas. Em algumas microrregiões a taxa de rotatividade passou de $200 \%$ (Tabela 2). Isso significa que os trabalhadores são admitidos e demitidos no mesmo ano. A rotatividade elevada prejudica a economia porque os trabalhadores não conseguem se estabelecer em um emprego, gerando custos para o empregador e para o governo. No caso das produções agropecuárias, as culturas sazonais influenciam no aumento da rotatividade laboral, pois os trabalhadores são contratados na época da plantação e da colheita e demitidos no intervalo das mesmas. A Rotatividade em excesso pode gerar instabilidade, rebaixamento de salário, impedimento do trabalhador para a qualificação profissional e uma potencial demanda pelo seguro desemprego e o FGTS.

Tabela 2 - Rotatividade masculina na agropecuária rondoniense de 2011 a 2016

\begin{tabular}{lcccccc}
\hline Microrregiões & 2011 & 2012 & 2013 & 2014 & 2015 & 2016 \\
\hline Porto Velho & 208,40 & 233,60 & 200,37 & 200,79 & 208,11 & 203,08 \\
Guajará-Mirim & 220,43 & 168,10 & 213,70 & 235,11 & 188,65 & 193,99 \\
Ariquemes & 214,20 & 193,89 & 211,70 & 222,43 & 203,34 & 193,36 \\
Ji-Paraná & 216,54 & 198,47 & 200,55 & 215,50 & 213,66 & 193,77 \\
Alvorada D'oeste & 213,95 & 205,47 & 225,00 & 240,25 & 197,47 & 185,09 \\
Cacoal & 211,20 & 200,32 & 218,38 & 211,91 & 199,72 & 204,54 \\
Vilhena & 204,44 & 200,21 & 215,37 & 196,86 & 196,56 & 184,05 \\
Colorado do Oeste & 217,36 & 200,43 & 208,85 & 196,82 & 206,49 & 194,41 \\
\hline
\end{tabular}

Fonte: Elaborado pelo autor, a partir de CAGED (2018).

Altos índices de rotatividade podem influenciar na baixa qualidade do emprego, pois a qualidade está relacionada a produtividade do trabalhador. Observa-se neste caso, a produtividade a partir da formação do capital humano, que é constituído pela escolarização e pela oferta de cursos e treinamentos pelas organizações. Contudo, se a rotatividade é alta, os trabalhadores não terão tempo hábil para aquisição destes conhecimentos oferecidos pela organização (GONZAGA, 1998).

No que se refere a rotatividade feminina das microrregiões de Rondônia, os resultados mostraram que existe uma alta rotatividade na agropecuária rondoniense, sendo que a microrregião de Alvorada D'Oeste teve a maior rotatividade em 2011 e 2016 (Figura 3). De acordo com o trabalho de Amaral e Silva (2015) a rotatividade 
na agropecuária da região Norte na década de 2000, a taxa média da rotatividade feminina foi de $133,15 \%$, valor inferior aos identificados no período analisado nesta pesquisa. Esta relação pode indicar que em Rondônia a rotatividade feminina no setor agropecuário está aumentando.

Figura 3 - Rotatividade feminina nas microrregiões de Rondônia de 2011 a 2016

\begin{tabular}{|c|c|c|c|c|c|c|c|c|}
\hline $\begin{array}{l}350,00 \\
300,00\end{array}$ & & & & & & & & \\
\hline 250,00 & & & & & & & & \\
\hline 200,00 & & & 晶: & 要官 & & 연 & & \\
\hline 150,00 & 學冒 & 楼目 & 侪盯 & 对官 & 淁官 & 琛目 & 桑目 & 缶自 \\
\hline $\begin{array}{r}100,00 \\
50,00\end{array}$ & 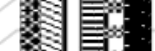 & 器目 & 梦得䭝 & 怼昷 & 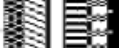 & 媇目: & 栄目 & 相亚 \\
\hline 0,00 & & & & & & & & \\
\hline & Porto Velho & $\begin{array}{c}\text { Guajará- } \\
\text { Mirim }\end{array}$ & Ariquemes & Ji-Paraná & $\begin{array}{c}\text { Alvorada } \\
\text { D'Oeste }\end{array}$ & Cacoal & Vilhena & $\begin{array}{c}\text { Colorado do } \\
\text { Oeste }\end{array}$ \\
\hline 2011 & 191,86 & 186,67 & 192,00 & 195,18 & 233,33 & 203,45 & 193,61 & 204,12 \\
\hline \& 2012 & 224,44 & 240,00 & 210,89 & 196,13 & 223,53 & 204,74 & 198,60 & 170,18 \\
\hline II 2013 & 192,46 & 150,00 & 229,21 & 205,23 & 181,82 & 208,03 & 195,23 & 208,82 \\
\hline-2014 & 206,34 & 200,00 & 243,00 & 233,67 & 229,63 & 193,50 & 183,79 & 176,87 \\
\hline - 2015 & 200,40 & 247,06 & 258,82 & 209,01 & 230,77 & 200,74 & 195,15 & 198,29 \\
\hline • 2016 & 208,10 & 180,00 & 265,98 & 251,28 & 314,29 & 210,44 & 192,59 & 200,00 \\
\hline
\end{tabular}

Fonte: Elaborado pelo autor, a partir de CAGED (2018).

Cabe indicar que no espaço rural, como no urbano, as mulheres precisaram romper barreiras para ter suas atividades laborais reconhecidas como atividades profissionais. Tendo em vista que tradicionalmente nos costumes relacionados ao Brasil, o homem é o responsável por atuar nas atividades relacionadas ao sistema produtivo da propriedade rural (HERRERA, 2012). Contudo, o cotidiano das propriedades rurais indica que as mulheres atuam em diferentes atividades, como aquelas relacionadas ao sistema produtivo (NEVES; MEDEIROS, 2013). Porém, estas práticas são identificadas como "ajudas" ao marido (BRUMER, 2000; SIMIÃO, 2002).

Análise do crescimento do emprego na agropecuária rondoniense

A taxa de crescimento do emprego mostra quanto o setor empregou ou desempregou nos anos analisados. A Figura 4 evidencia o crescimento do emprego masculino na agropecuária nas microrregiões de Rondônia. Os resultados mostraram que as microrregiões perderam mão de obra empregada no período analisado. A microrregião de Porto Velho teve crescimento negativo do emprego para todos os anos analisados, sendo que em 2016, sua taxa de desemprego alcançou $-14,03 \%$ e na média teve taxa negativa de $-6,47 \%$. 
Figura 4 - Crescimento do emprego formal masculino nas microrregiões de Rondônia de $2011 / 2016$

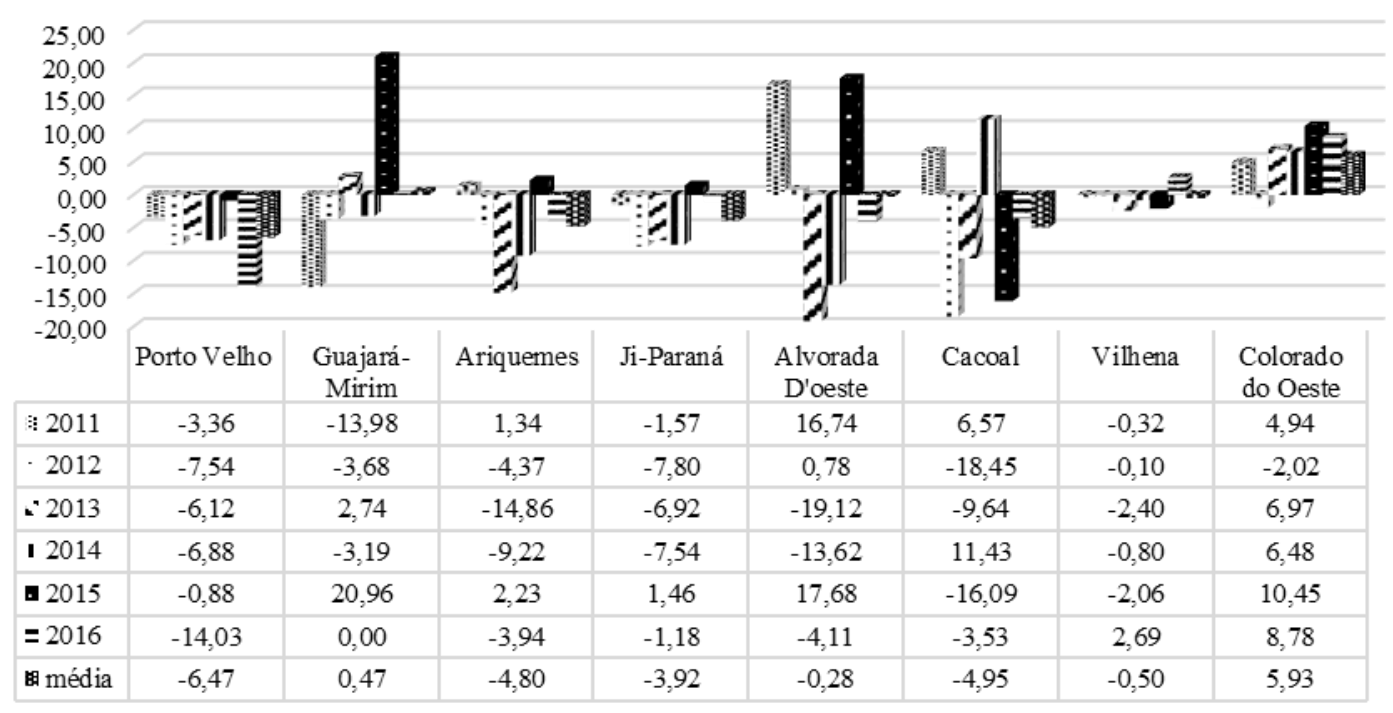

Fonte: Elaborado pelo autor, a partir de CAGED (2018).

A microrregião de Guajará-Mirim obteve um crescimento expressivo em 2015, mas na média cresceu apenas $0,47 \%$ no período analisado. O setor agrícola está concentrado mais a leste do Estado. A região Madeira-Guaporé possui significativas áreas de reservas ambientais, por isso sua utilização das terras para a agropecuária é reduzida. Fazem parte dessa mesorregião as microrregiões de Guajará-Mirim e Porto Velho.

O crescimento do emprego na microrregião Colorado do Oeste manteve-se positivo para todos os anos, com exceção de 2012, que teve taxa negativa de $2,02 \%$. A Figura 4 mostra que houve crescimento do emprego em apenas duas microrregiões, Guajará-mirim e Colorado do Oeste. A produção agropecuária de Rondônia é baseada na produção familiar, poucas são as propriedades não familiar ou patronal. Um bom exemplo é a pecuária leiteira que em grande parte vem da agricultura familiar e emprega pouca tecnologia. A pecuária de corte é mais forte no Estado e vem crescendo a cada dia.

Para Borja (2005) o mercado de trabalho, torna-se interessante para a realização de pesquisas devido suas características que podem estar vinculadas a questões de políticas sociais e que refletirão em outros elementos da sociedade, a partir da interação entre trabalhadores e empresas. Um exemplo é a constatação disponibilizada por Soares et al. (2016), a qual, resulta em características que influenciam a existência da pobreza rural nas regiões Norte e Nordeste do país, e que estão, em muitos casos atrelados ao mercado de trabalho. 
Outro fator analisado foi o crescimento do emprego feminino nas microrregiões de Rondônia. Os resultados mostraram que em 2011 apenas a microrregião de Ji-Paraná desempregou, com uma taxa negativa de 9,64\%. As microrregiões de Alvorada D'oeste e Colorado do Oeste obtiveram taxas expressivas de crescimento do emprego em 2011 , com $33,33 \%$ e $47,42 \%$ respectivamente. As microrregiões tiveram taxas negativas do emprego feminino para os anos de 2015 e 2016, o que pode ser explicado pela crise econômica que se iniciou no Brasil em 2015 (Figura 5).

Figura 5 - Crescimento do emprego feminino nas microrregiões rondoniense 2011 a 2016

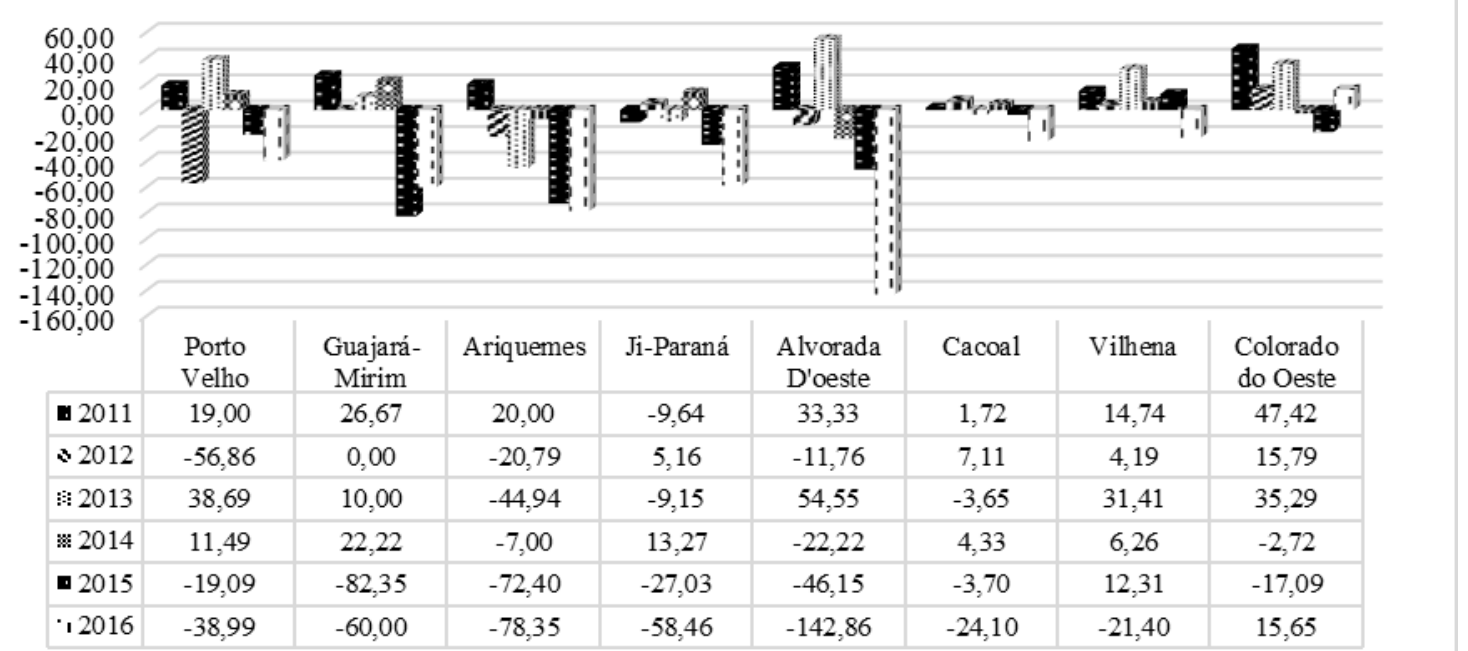

Fonte: Elaborado pelo autor, a partir de CAGED (2018).

A Tabela 3 mostra a estatística descritiva e o crescimento da rotatividade masculina e feminina para o período analisado. Os resultados evidenciam uma queda na rotatividade masculina para todas as microrregiões. Para as mulheres a rotatividade aumentou em quase todas as microrregiões e as que diminuíram não chegou a 1\%. Isso mostra que homens e mulheres estão sujeitos as mudanças no emprego agropecuário.

Tabela 3 - Estatística descritiva e crescimento anual da rotatividade nas microrregiões de Rondônia, 2011/2016

\begin{tabular}{|c|c|c|c|c|c|c|c|c|c|c|}
\hline \multirow{3}{*}{ Microrregião } & \multicolumn{8}{|c|}{ Estatísticas descritivas } & \multirow{2}{*}{\multicolumn{2}{|c|}{$\begin{array}{c}\text { Crescimento } \\
\text { anual } \\
\text { da rotatividade }\end{array}$}} \\
\hline & \multicolumn{2}{|c|}{ Mínimo } & \multicolumn{2}{|c|}{ Máximo } & \multicolumn{2}{|c|}{ DP } & \multicolumn{2}{|c|}{ Média } & & \\
\hline & Masc. & Fem. & Masc. & Fem. & Masc. & Fem. & Masc. & Fem. & Masc. & Fem. \\
\hline Porto Velho & 200,37 & 191,86 & 233,60 & 224,44 & 12,52 & 12,11 & 209,06 & 203 & $-0,52$ & 1,64 \\
\hline Guajará-Mirim & 168,10 & 150,00 & 235,11 & 247,06 & 24,31 & 37,12 & 203,33 & 200 & $-2,52$ & $-0,72$ \\
\hline Ariquemes & 193,36 & 192,00 & 222,43 & 265,98 & 11,68 & 28,42 & 206,49 & 233,32 & $-2,03$ & 6,74 \\
\hline Ji-Paraná & 193,77 & 195,18 & 216,54 & 251,28 & 9,95 & 22,56 & 206,41 & 215,08 & $-2,20$ & 5,18 \\
\hline Alvorada D'oeste & 185,09 & 181,82 & 240,25 & 314,29 & 19,72 & 43,11 & 211,21 & 235 & $-2,86$ & 6,14 \\
\hline Cacoal & 199,72 & 193,50 & 218,38 & 210 , & 7,38 & 5,96 & 207,68 & 203,48 & $-0,64$ & 0,68 \\
\hline Vilhena & 184,05 & 183,79 & 215,37 & 198,60 & 10,31 & 5,02 & 199,58 & 193,16 & $-2,08$ & $-0,11$ \\
\hline $\begin{array}{l}\text { Colorado do } \\
\text { Oeste }\end{array}$ & 194,41 & 170,18 & 217.36 & 208,82 & 8.54 & 15.70 & 204.06 & 193.05 & $-2,21$ & $-0,41$ \\
\hline veste & 154,41 & 170,10 & 217,00 & & & & $\angle U 4,00$ & & $-2, \angle 1$ & $-0,41$ \\
\hline
\end{tabular}

Fonte: Elaborado pelo autor, a partir de CAGED (2018). 
O desvio padrão mostra que os dados são dispersos da média em algumas microrregiões e próximos da média em outras, tanto para homens como para mulheres. Os resultados demonstram que homens e mulheres não têm segurança ou garantia de permanência no emprego agropecuário, o que é uma característica desse setor.

A Tabela 4 mostra a estatística descritiva e a taxa de crescimento do emprego nas microrregiões de Rondônia. Os dados confirmam o crescimento do desemprego no estado, tanto para homens como para mulheres. O desvio padrão mostra que os dados masculinos estão mais próximos da média. Já os dados femininos são muito distantes da média, ou seja, existem dados discrepantes que influenciam na média.

Tabela 4 - Estatística descritiva do emprego e taxa de crescimento anual do emprego masculina e feminina nas microrregiões rondoniense de 2011 a 2016

\begin{tabular}{|c|c|c|c|c|c|c|c|c|c|c|}
\hline \multirow{3}{*}{ Microrregião } & \multicolumn{8}{|c|}{ Estatísticas descritivas } & \multirow{2}{*}{\multicolumn{2}{|c|}{$\begin{array}{c}\text { Crescimento } \\
\text { anual } \\
\text { do emprego }\end{array}$}} \\
\hline & \multicolumn{2}{|c|}{ Mínimo } & \multicolumn{2}{|c|}{ Máximo } & \multicolumn{2}{|c|}{$\mathrm{DP}$} & \multicolumn{2}{|c|}{ Média } & & \\
\hline & Masc. & Fem. & Masc. & Fem. & Masc. & Fem. & Masc. & Fem. & Masc. & Fem. \\
\hline Porto Velho & $-14,03$ & $-56,86$ & $-0,88$ & 38,69 & 4,46 & 33,56 & $-6,47$ & $-7,62$ & 33,08 & $-215,46$ \\
\hline Guajará-Mirim & $-13,98$ & $-82,3$ & 20,96 & 26,67 & 11,53 & 41,88 & 0,47 & $-13,91$ & $-100,00$ & $-217,61$ \\
\hline Ariquemes & $-14,86$ & $-78,35$ & 2,23 & 20,00 & 6,46 & 35,07 & $-4,80$ & $-33,91$ & $-224,06$ & $-231,40$ \\
\hline Ji-Paraná & $-7,80$ & $-58,46$ & 1,46 & 13,27 & 3,98 & 23,45 & $-3,92$ & $-14,31$ & $-5,68$ & 43,41 \\
\hline Alvorada D'oeste & $-19,12$ & $-142,86$ & 17,68 & 54,55 & 15,24 & 63,53 & $-0,28$ & $-22,52$ & $-175,52$ & $-233,78$ \\
\hline Cacoal & $-18,45$ & $-24,10$ & 11,43 & 7,11 & 12,09 & 10,20 & $-4,95$ & $-3,05$ & $-188,31$ & $-269,46$ \\
\hline Vilhena & $-2,40$ & $-21,40$ & 2,69 & 31,41 & 1,82 & 15,78 & $-0,50$ & 7,92 & $-253,04$ & $-207,74$ \\
\hline Colorado do Oeste & $-2,02$ & $-17,09$ & 10,45 & 47,42 & 4,34 & 21,62 & 5,93 & 15,72 & 12,21 & $-19,88$ \\
\hline
\end{tabular}

Fonte: Elaborado pelo autor, a partir de CAGED (2018).

Fica evidente pelo crescimento anual do emprego que apenas a microrregião de Ji-Paraná obteve crescimento positivo para o sexo feminino, com $43,41 \%$, e para os homens o crescimento positivo foi nas microrregiões de Porto Velho $(33,08 \%)$ e Colorado do Oeste $(12,21 \%)$, as demais microrregiões tiveram altos índices de desemprego para todo o período analisado. A microrregião de Ji-Paraná se destaca na produção da pecuária, principalmente na produção de leite, pois os municípios com as maiores produções estão inseridos nessa microrregião. Também tem destaque para a produção de arroz, milho, café, além de possuir diversos armazéns para a produção. A Microrregião de Ji-Paraná é a segunda mais populosa do estado, ficando atrás apenas da microrregião de Porto Velho. A microrregião do Colorado do Oeste possui cinco municípios na sua formação e faz divisa com o Mato Grosso, é destaque na produção de milho, soja, café e na pecuária tem maior potencial na produção de gado de corte. A média masculina foi maior e mais homogênea do que a média feminina. 
Observa-se ainda, em relação ao contexto do trabalho rural, na Figura 6, a área plantada no período de 2011 a 2016 para o cultivo de soja, milho e arroz. A quantidade de hectares plantados em 2011 é maior que nos demais anos, podendo indicar uma necessidade menor do emprego de mão de obra nos demais anos, se comparado a 2011. Além disso, a figura traz a informação do percentual de ocupação produtiva por cultura, sendo a soja, o milho e o arroz, aqueles com maior ocupação de hectares. Com o decorrer dos anos, é visível o aumento da produção da soja, em todo o período temporal e do milho até 2015. Em contrapartida, o arroz tem sua área produtiva reduzida. A alteração na produção agrícola para o binômio soja/milho pode ser outro indicativo de redução de necessidade de mão de obra, pois são culturas, com tecnificação desenvolvida.

Figura 6 - Percentual de hectares plantados por culturas produtivas mais frequentes em Rondônia, período 2011 - 2016

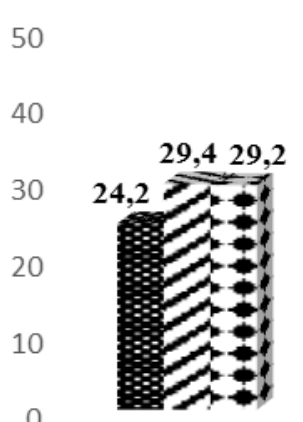

2011

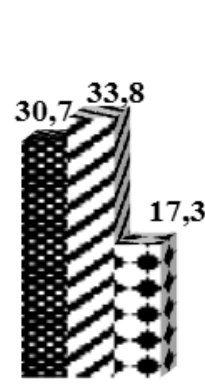

2012

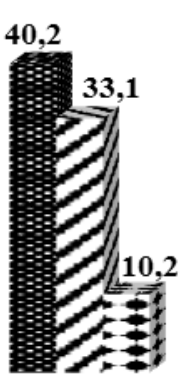

2013

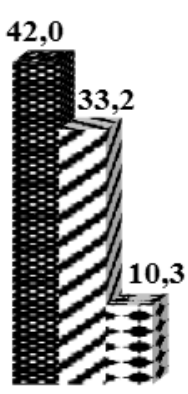

2014

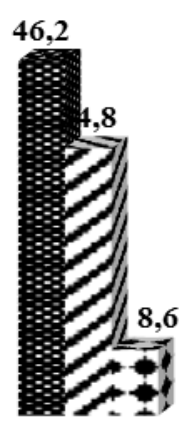

2015

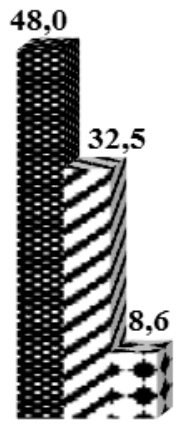

2016

soja $v$ Milho $m$ Arroz

Fonte: Elaborado pelos autores a partir de IBGE (2017b).

Diante destas características, ressalta-se que nos últimos anos a produção realizada no espaço rural, tem tido ganhos de produtividade e tecnologia (GASQUES et al., 2014; CASTRO et al., 2015). Ambos contribuem com as práticas rurais, mas o uso das tecnologias tende a suprir a mão de obra utilizada no campo (WOLFERT et al., 2017; PIVOTO et al., 2016).

\section{CONSIDERAÇÕES FINAIS}

O estudo sobre admissão e demissão no mercado de trabalho tem contribuído de forma significativa para a compreensão de seu funcionamento. Sendo que o conhecimento sobre este mercado possibilita a criação de políticas públicas que melhorem a vida dos trabalhadores da agropecuária, políticas que incentivem a produção agrícola e pecuária, elevando assim, o número de empregos e a qualidade de vida dos trabalhadores. 
Apesar da importância do tema, o estado de Rondônia possui poucos trabalhos publicizados sobre o tema. Além disso, os estudos realizados não abrangem especificamente os trabalhadores da agropecuária. Este trabalho fez um estudo das taxas de rotatividade e crescimento líquido do emprego, abordando a indicação da divisão do mercado de trabalho agropecuário, para homens e mulheres, nas microrregiões que compõem o estado.

Os resultados encontrados demonstraram que o emprego formal na agropecuária por sexo está sendo reduzido no decorrer dos anos estudados, ofertando cada vez menos postos de trabalho nesse setor da economia. Os homens são os mais afetados pela flexibilidade do mercado. Isso porque são eles que trabalham diretamente com a produção no campo. Considerando que a mecanização em maior ou menor medida está presente nos espaços rurais, trabalhadores que atuam diretamente com as atividades produtivas, podem ser reduzidos com o aumento da mecanização. Além disso, a flexibilidade dos postos de trabalho é muito elevada, e esse fato se deve a alta taxa de rotatividade para homens e mulheres.

A criação líquida de emprego na agropecuária em Rondônia é negativa, tanto para homens como para mulheres. Os níveis de desempregos no setor estão cada vez mais elevados. Uma preocupação é saber como os trabalhadores rurais vão conseguir se manter no campo sem a garantia de sustento. Ou onde estes trabalhadores serão realocados, caso decidam migrar para o espaço urbano.

Futuros trabalhos podem identificar o emprego na agropecuária por nível de escolaridade e nível salarial. E identificar quais fatores influenciam na permanência dos trabalhadores no trabalho do campo, a partir de pesquisa qualitativa. Este trabalho está limitado à base de dados (CAGED online) que não permite identificar o que é criação de posto de trabalho e o que é apenas reposição de vagas, levandose em conta que os dados estão agregados. Outra limitação está nas variáveis que explicam a rotatividade.

\section{REFERÊNCIAS}

IDARON - Agência de Defesa Sanitária Agropastoril do Estado de Rondônia. Produção de soja em Rondônia tem expectativa de crescimento maior que a média nacional. Porto Velho - RO, 2016. Disponível em: <http://www.rondonia.ro.gov.br/2016/11/144133/>. Acesso em: 28 dez. 2017. região Norte. Revista de Economia Agrícola, n. 2, p. 78 - 89, 2015. 
BORJAS, G. J. Labor Economics. Harvard University, 3º Ed. New York - EUA, 2005.

BRUMER, A. Gênero e agricultura: a situação da mulher na agricultura do Rio Grande do Sul. Estudos Feministas, Florianópolis, 2000.

BRUSCHINI, C.; LOMBARDI, M. R. A Bipolaridade do Trabalho Feminino no Brasil Contemporâneo. Cadernos de Pesquisa, n. 110, p. 67-104, 2000.

BUAINAIN, A.M.; DEDECCA, C. S. Emprego e Trabalho na Agricultura Brasileira. In: Miranda, C.; Tibúrcio B. (org.). Série Desenvolvimento Rural Sustentável. Instituto Interamericano de Cooperação para a Agricultura - IICA, Brasília, 2008. Disponível em: <http://www.iica.int>. Acesso em: 15 set. 2017.

BUAINAIN, A. M.; ALVES, E.; SILVEIRA, J. M.; NAVARRO, Z. O mundo rural no Brasil do século 21: a formação de um novo padrão agrário e agrícola. Embrapa, p. 1 - 1186, 2014.

CAGED - Cadastro de Empregados e Desempregados. Postos Formais. Disponível em:< portal.mte.gov.br/imprensa/caged>. Acesso em: 10 maio de 2018.

CASTRO, N.R.; SILVA, A.F. BARROS, G.S.C., FACHINELLO, A.L.; GILIO, L. Evolução das principais atividades do agronegócio de São Paulo entre 2008 e 2013. 53ํㅡㄴ Congresso da Sociedade Brasileira de Economia e Sociologia Rural - SOBER. Anais. João Pessoa, PB, 26 a 29 de julho de 2015.

CARNEIRO, M. J. Ruralidade: novas identidades em construção. Estudos Sociedade e Agricultura, v. 11, p. $53-75,1998$.

COELHO, A. M; CORSEUIL, C. H. Diferenciais salariais no Brasil: um breve panorama. Texto para discussão $n^{\circ} 898$, Rio de Janeiro, 2002. Disponível em:

<http://www.ipea.gov.br/portal/images/stories/PDFs/TDs/td_0898.pdf>. Acesso em: 15 mar. 2018.

DAVIS, S. J.; HALTIWANGER, J. Gross job creation, gross job destruction, and employment reallocation. The Quarterly Journal of Economics, v. 107, n. 3, p. 819 - 863, 1992.

DE ALMEIDA, R.; ALVES, M.E. Benefícios do trabalho formal para os prestadores de serviços em obras de alvenaria na cidade de Tangará da Serra /MT. Revista UNEMAT de Contabilidade, v.3, n.5, 2014.

DUARTE, F. S.; MENDES, A. M. B. Da escravidão a servidão voluntária: perspectivas para a clínica psicodinâmica do trabalho do Brasil. Revista de Estudos Organizacionais e Sociedade, v. 2, n. 2, p. $1-61,2015$.

Empresa Brasileira de Pesquisa Agropecuária - EMBRAPA. Boletim Agropecuário de Rondônia: evolução da produção agropecuária. Porto Velho, 2018. Disponível em https://www.embrapa.br/boletim-agropecuario. Acesso em: 15 mar. 2018.

EMPRESA ESTADUAL DE ASSISTÊNCIA TÉCNICA E EXTENSÃO RURAL - EMATER. Nova Mamoré lidera produção leiteira em Rondônia. Porto Velho, RO, 2018. Disponível em: <http://www.emater.ro.gov.br/ematerro/2018/01/10/nova-mamore-lidera-producaoleiteira-em-rondonia>. Acesso em: 16 mar. 2018.

FRANCO, L. F.; CARDOSO, J. L. Responsabilidade civil e penal do profissional contábil. ConTexto, v. 9, n. 15, p. $1-24,2009$. 
GASQUES, J. G.; BASTOS, E.T.; VALDES, C.; BACCHI, M.R.P. Produtividade da Agricultura Brasileira: Resultados Para o Brasil e Estados Selecionados. Anais... Sober, $52^{\circ}$ Congresso, Goiânia, - GO, 2014.

GONZAGA, G. Rotatividade, qualidade do emprego e distribuição de renda no Brasil. Revista de Economia Política, v. 18, n. 1, p. 120-140, 1998.

GROGAN, A. Smartspecial - smartfarming. Engineering \& Technology, 7 (6), 2012.

HERRERA, K. M. Uma análise do trabalho da mulher rural através da perspectiva da multifuncionalidade agrícola. Seminário Internacional Fazendo Gênero 10. Anais

Eletrônicos. Florianópolis, 2012.

INSTITUTO BRASILEIRO DE GEOGRAFIA E ESTATISTICA-IBGE. Censo Agropecuário. 2006. Disponível em:

<http://www.ibge.gov.br/home/estatistica/economia/agropecuaria/censoagro/default.shtm>. Acesso em: nov. 2017.

INSTITUTO BRASILEIRO DE GEOGRAFIA E ESTATISTICA-IBGE. Censo Demográfico. 2010. Disponível em:<http://www.ibge.gov.br/estadosat/temas.

php?sigla=ac\&tema=sinopse_censodemog2010>. Acesso em: 27 dez. 2017.

INSTITUTO BRASILEIRO DE GEOGRAFIA E ESTATISTICA-IBGE. Malhas digitais. 2015. Disponível em: <https://mapas.ibge.gov.br/bases-e-referenciais/bases-cartograficas/malhasdigitais.html>. Acesso em: 27 dez. 2017.

INSTITUTO BRASILEIRO DE GEOGRAFIA E ESTATISTICA-IBGE. Estados. 2017a.

Disponível em: <https://cidades.ibge.gov.br/>. Acesso em: 27 dez. 2017.

INSTITUTO BRASILEIRO DE GEOGRAFIA E ESTATISTICA-IBGE. Produção Agrícola

Municipal. 2017b. Disponível em: <https://sidra.ibge.gov.br/pesquisa/pam/tabelas $>$. Acesso em: 28 dez. 2017.

INSTITUTO BRASILEIRO DE GEOGRAFIA E ESTATISTICA-IBGE. Série Relatórios

Metodológicos. Rio de Janeiro, 2004. Disponível em: <http://www.ibge.gov.br>. Acesso em: 06 jan. 2018.

KAGEYAMA, A. O subemprego agrícola nos anos 90. Nova Economia, v. 7, n. 1, p. $83-$ 98, 1997.

NEVES, D. P.; MEDEIROS, L. S. Mulheres Camponesas: trabalho produtivo e engajamentos políticos. Alternativa: Niterói, p. 1 - 434, 2013.

PIVOTO, D.; MORES, G. V.; SILVA, R. F.; KAWANO, B. R.; TALAMINI, E. Smart Farming Pode Trazer Ganhos para o Agronegócio? Agroanalysis, p. 31-33, 2016.

RELAÇÃO ANUAL DE INFORMAÇÕES SOCIAIS - RAIS. Rondônia, 2016. Disponível em: <http://pdet.mte.gov.br/rais?view=default>. Acesso em: 15 mar. 2018.

SIMIÃO, D. S. As coisas fora do lugar - gênero e o potencial de programas de geração de emprego e renda. In: Perspectivas de Gênero: debates e questões para as ONGs. 1. ed. Recife, PE: SOS Corpo Gênero e Cidadania, p. 80- 93, 2002.

SOARES, S.; DE SOUZA, L.; SILVA, W.; SILVEIRA, F. G.; CAMPOS, A. Perfil da pobreza: Norte e Nordeste rurais. Centro Internacional de Políticas para o Crescimento Inclusivo. p.1 $-44,2016$. 
STADUTO, J. A. R.; SHIKIDA, P. F; BACHA, C. J. C.Alteração na composição da mão-deobra assalariada na agropecuária brasileira. Agric., v. 51, n. 2, p. 57 - 70, 2004.

WOLFERT, S.; GE, L.; VERDOUW, C.; BOGAARDT, M.-J. Big Data in Smart Farming - A review. Agricultural Systems, v. 153, p. $69-80,2017$.

\section{NOTAS DE AUTOR}

\section{CONTRIBUIÇÃO DE AUTORIA}

Josineide Aquino da Silva Amaral - Concepção. Coleta de dados, Análise de dados, Elaboração do manuscrito, revisão e aprovação da versão final do trabalho

Luciana Virginia Mario Bernardo - Concepção e elaboração do manuscrito. Coleta de dados, Participação ativa da discussão dos resultados; Revisão e aprovação da versão final do trabalho.

Jefferson Andronio Ramundo Staduto - Concepção. Elaboração do manuscrito, revisão e aprovação da versão final do trabalho

\section{FINANCIAMENTO}

O presente trabalho foi realizado com apoio da Coordenação de Aperfeiçoamento de Pessoal de Nível Superior Brasil (CAPES) - Código de Financiamento 001.

\section{CONSENTIMENTO DE USO DE IMAGEM}

Não se aplica.

APROVAÇÃO DE COMITÊ DE ÉTICA EM PESQUISA

Não se aplica.

\section{CONFLITO DE INTERESSES}

Não há conflitos.

\section{LICENÇA DE USO}

Este artigo está licenciado sob a Licença Creative Commons CC-BY. Com essa licença você pode compartilhar, adaptar, criar para qualquer fim, desde que atribua a autoria da obra.

\section{HISTÓRICO}

Recebido em: 29-06-2019

Aprovado em: 07-05-2020 